\title{
E-Business Management: Concepts and Successful Factors Abdulrahman Alshamlan
}

Alshamlan9@hotmail.com

\begin{abstract}
The merge of the information technology and the web standards have formed the electronic business " $E$ business". Succession in e-business will need organizations to revise their strategies and goals to meet market rules of demand and supply. Conversion of ordinary business into e-business has forced organizations to be redesigned and reshaped. E-business is a combination of economic, technology and market forces that reinvented strategies of traditional business. The business process is counted to use the power of computers and communication networks which are known as Internet. This can allow organizations to stay competitive and more efficient. Also, new business models have been introduced and implemented in a variety of ways. E-business and Internet have enforced organizations to use new and combined models. This enforcement drove organizations to seek and create solutions to the issues of change management. One of these issues is business process reengineering which is redesigning the processes of an organization's business to the optimum to meet their goals.
\end{abstract}

\section{Introduction}

Internet is changing the international economy. By exploring the abilities and possibilities of information technology, computers and communication networks which have created a very cheep way for organizations to transform their business and activities, enhance their relationships with their partners and other stockholders and create new market opportunities. The ease and world wide usage of Internet have increased the challenge and competition between organizations to invent and create new methods to be leaders in e-business. This report reviews the factors of change management in implementing e-business and assesses the importance of each. It concludes with the main success factors in managing change, organizational structure change in response to e-business and human aspects management in implementation of organizational change. 


\section{What is Management?}

Management is the process used to accomplish organizational goals through planning, organizing, directing and controlling organizational objectives. The planning is forecasting and determining the best strategies to achieve organizational goals and objectives. While the organizing is the implementation of those plans to achieve the goals and objectives of the organization by designing the organizational structure, setting employees and employment rules and regulations and creating conditions and systems that insure that everyone and everything works together. After that, directing is required to guide and motivate others to work effectively to achieve the goals and objectives of the organization. Finally, business will need controlling to determine whether or not the organization is progressing towards its goals and objective and how necessary to take corrective actions if needed (Nickels et al, 1990).

Good managers will always have contingency plans as backup plans in case primary ones fail. Also, a model known as management by walking around is very effective. It requires managers to interact with employees and customers to learn their wants, needs and suggestions (Nickels et al., 1990). This kind of managements will lead managers to new ideas in marketing, sales, etc. which can change goals, objectives, structure and culture of the organization. This change by itself will need management.

\section{What Is E-Business?}

It is a method of running business using Internet where all the financial transactions can be conducted over web with suppliers and customers online. Industrially, e-business is defined as "All about time cycle, speed, globalization, enhanced productivity, reaching new customers and sharing knowledge across institution for competitive advantage" said by Lou Gerstner, chief executive of IBM. It is a business change where adoption to constraint and continual change is needed to manage transitions smoothly, to improve operating efficiencies that will strengthen the value provided by the business to the customers. Going far beyond buying and selling over Internet, ebusiness is the relation to the whole chain of organization business from raw materials through to satisfied customers (E-Business Systems Integration Center, uda).E-Business is more than the implementation and operation of an electronic front-end. It requires the development of new strategies for using and managing realtime information, reorganize inventories and distribution system activities, and establishing new inter-organizational relationships.

\section{Why E-Business?}

The opportunities that ebusiness may present to an organization business are vary. Some of these opportunities include improving existing business process and reduction of transaction cost. But the 
survival challenge and competition are the main reason of turning into e-business. Its advantages are increasing purchasing opportunities and options within an open market, round-the-clock services and fast and accurate information exchange. While the disadvantages can be differently measured by organizations depends on geographical location, Internet bandwidth limitation, applying new skills and recruitment and difficulty in measuring the return on investment. (E-Business Systems Integration Center, udb).

\section{Becoming an E-Business}

The Internet gave the opportunities to consumers and businesses to quickly and easily buy and sell products by providing some features like electronic presentation of goods and services, on-line ordering and payment processing, automated customer account inquiries and on-line bill presentation. Consumers are having an advanced customer services by delivering on-line and dynamic solutions to them. (EBusiness Solutions, ud). To take the advantages of the opportunities that ebusiness is representing requires a strategic planning and forecasting, re-discovering business resources, manufacturers, suppliers, distributors and other stakeholders. Wither it is business to business (B2B) or business to consumer (B2C) companies, both will have to manage the change that will be necessitated by e-business in order making the benefit of e-business (Chaffey, 2004). E-business requires understanding the business needs and skills and resources to design, implement and maintain superior solutions. It will require changes in the organization structure, culture and staff responsibilities. It needs knowledge, experience and tools that can deliver the promise and potential of e-business (Chaffey, 2004).

\section{E-Business Aspects of Change}

Chaffey (2004) said that main change aspects required are market and business models, business process, organization structure, culture and staff responsibilities and technology infrastructure changes. He added that change aspects will be key factors for an organization to be agile to responding to market place changes and delivering competitive customer service. Also, Pettigrew and Whipp (1993) have emphasized that a successful change will be a result of the interaction between those aspects and defined them as content, process and context or what, how and where (See figure 1). 


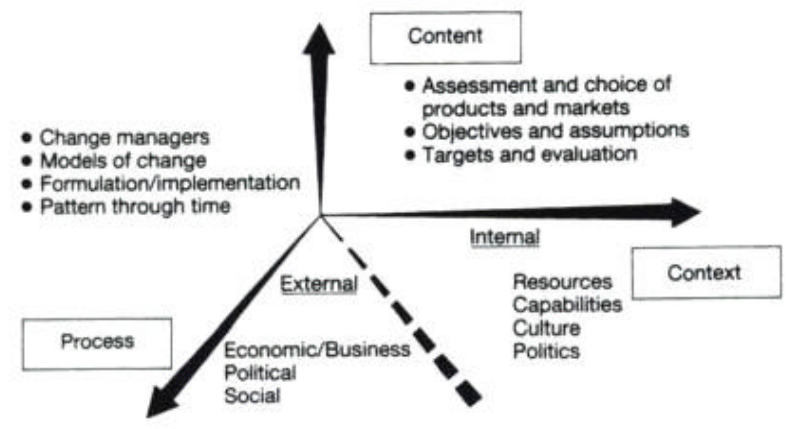

Figure 1 Aspects of Change: Three Essential Dimensions (Pettigrew and Whipp, 1993)

What are the objectives, purpose and goals of the change, how the change can be implemented, and where the change will be, is it internal, external or both? Answering these questions will help to solve the issue of change management in converting the business from ordinary basis into e-business and achieving a successful result (Value Based Management.Net, 2005a).

\section{Market Place and Business Model - What?}

Integrating digital marketing into an organization will need to redesign the objectives, purpose and goals of the organization. Managers will face challenges to define strategies and best practice approaches to meet the new goals of the organization and to set practical solutions to those challenges. But, Achieving those goals and objectives by applying digital technologies emphasizes the importance of deploying Ebusiness to align with and impact business and marketing objectives and using technology to support this, rather than leading with technologies and applications. From this definition we can understand that technologies like web, e-mail, mobile, etc should not drive organizations to get involved with the technology itself and continue developing and building applications. But, they should concentrate on the business returns from gaining new customers and maintaining relationships with existing customers (Chaffey and E-Consultancy, 2005).

Organizations can use a capability maturity model to Review current approaches and identify areas for improvement, benchmark with competitors who are in the same market sector / industry and in different sectors, dentify best practice from more advanced adopters, set targets and develop strategies for improving capabilities. Organizations can determine their e-business capabilities with other organizations by using a 5 stage capability maturity model (CMM). The five stages of this model are unplanned, diffuse management, centralized management, decentralized operations and integrated and optimized. CMM concentrates on content and managing the integration with enough experience, visitor acquisition by 
Abdulrahman Alshamlan

structuring approaches in certain areas, controlling the conversion to meet objectives and goals, retention the integration with market activities and optimizing the approaches (Chaffey and E-Consultancy, 2005).

\section{Business Process Reengineering (BPR) - How?}

E-business has driven organizations to open markets and competition where no longer to enjoy the protection of our own country's borders as we could in the past. Today, in a global economy, worldwide customers are more sophisticated and demanding. This will require organizations to examine new goals that need redesigning work and business process. According to Hammer and Champy this can be a radical redesign from the ground up (Answers.com, ud). They called it reengineering that is determined by open markets and competition (Answers.com, ud). BPR should deal with processes redesign and manage the change rather than automate existing tasks and functions (Answers.com, ud). It is a methodology that needed to do the change. An example of BPR methodology is the organizational change process (OCP). It comprises four major phases. These are preparation, acceptance, implementation and commitment (ebiz.enable, 2005a). If change has been identified, then a decision to proceed should be taken, and communicated throughout the organization. Then, BPR implementation can lead to successful outcomes. BPR at beginning will need to organize pressure for change. For change to be effective, it needs to be implemented at all levels. Employees should share the vision for the organization and also for themselves as individuals (Our South West, 2004).

\section{Organization Structure, Culture and Staff Responsibilities - Where?}

The employment status of staff can affect their loyalty to the organization and create resistance to the change. The attitude and behaviour within an organization usually set by senior employees, so their influence on organizational culture is important. Also, in the managerial level, problems can occur when mangers won't assign the needed resources to the project (ebiz.enable, 2005b). Prosci has defined the elements that may create a desire not to change as fear of job loss, discontent with the current state, career advancement, acquisition of power or position and trust and respect for leadership. Those are some of the internal aspects that can affect the change while a union can be considered as an external one where it may have some impacts on the change (Change management learning centre, 2005a). The factors which influence the expectations that individuals and groups are likely to have of an organization are vary. Those factors can have effects on the strategic development of the organization and should be analyzed to identify the expectations of groups and individuals within the organization and wither the strategies reflect the influence of any of those factors. Also, how would those factors help or hinder the changes which would be needed to pursue new strategies should be considered in that analysis (Johnson and Scholes, 1993). 


\section{Technology Infrastructure Changes}

E-business will impose to understand some techniques and terms like on-line and off-line communication, extranet, etc. and these techniques will require a knowledge management, for example on microenvironment like customers, suppliers and computers. The knowledge transfer will be a key to competitiveness (Chaffey, 2004).

PTC Global Services are suggesting to Automat the change process and provide visibility that can reduce the number of late stage engineering changes and reduce the overall number of changes. Although they think the benefits of an automated change management process can be clearer and better then using methods to implement the solution. Their solution is to Assess, Deploy and Optimize an approach that leverages industry accepted processes such as CMII. It is a consultancy services that can assess to adopt a clear strategy and cost and benefit analysis for improving change management. Then, deploy the solution by offering installation, configuration, and training services. After that they can improve the solution of the change management process by optimizing it (PTC Global Services, 2005).

\section{E-Business Aspects of Success}

The enforcement of a change will need to process a strategic management to specify objectives, develop policies and allocate resources to implement plans (Answers.com, udb). Change management learning center (2005b) has defined some components of change management based on Prosci's research which was conducted with more than 400 organizations in the last five years. The se components are change management process, readiness assessments, communication and communication planning, managers training for change management, employees training and development, sponsorships activities, resistance management, feedback analysis and finally the rewards for succession. Those components actually can be considered as tools or guidelines for applying an effective change and approaching the desired goals of an assigned project. But the aspects of success for e-business are well defined by Chaffey (2004). He defined those aspects as leadership commitment, project management and employee acquisition, retention and ownership. He added that examining those aspects can be on a large-scale project or on a smaller scale that could be a single project. The examination may affect the whole business of a firm. So, it is better to make it on a single project that can be considered as a pilot for the large-scale project. Figure 2 shows the interaction between aspects of change that required to be assessed in order to maximize the benefits of ebusiness and aspects of success that required to be implemented to achieve those benefits and goals of an organisation. 


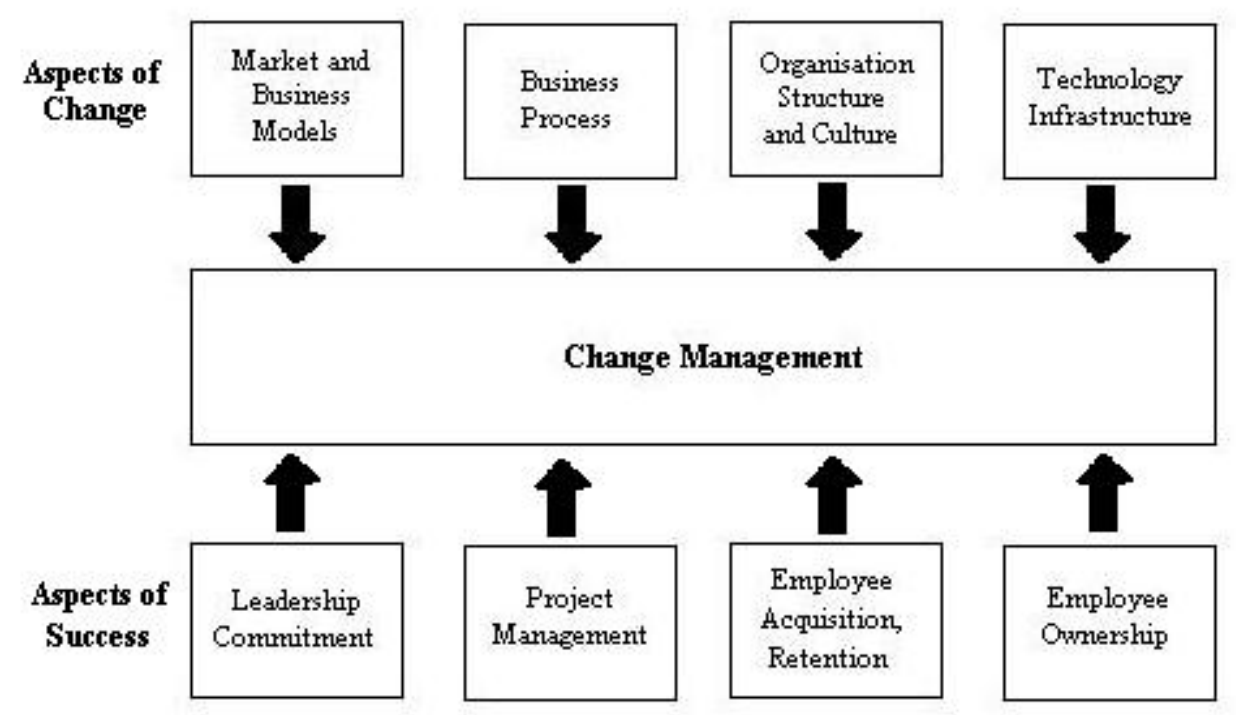

Figure 2: Key Factors In Achieving Change (Chaffey, 2004).

\section{Leadership Commitment}

Kotter (1990) suggested an eight change phases' model for successful leadership. He said that a leadership has to establish a scene of urgency, create a coalition, develop a clear vision and share it, empower people to clear obstacles, secure short-term wins, consolidate and keep moving and anchor the change (Value Based Management.Net, 2005b). The model can be considered as management commitment where the president or senior management can play the role of leadership that should drive the project to the desired objectives (ebiz.enable, 2005c). But Prosci is considering sponsorship as the most important success factor which will need plan for sponsor activities and help key business leaders carry out those plans (Change management learning center, 2005b).

\section{Project Management}

When developing an e-business strategy, it is essential to consider business process reengineering (BPR) methodology which is an effective tool to process and manage the change. BPR; as mentioned earlier; comprises four phases. First, the preparation phase which will require the leaderships to make and encourage the employees and other stakeholders to understand and accept the change (ebiz.enable, 2005d). Next, the acceptance phase which will resolve the resistance by training the employees and encourage them to learn new skills (ebiz.enable, 2005e). After that, the implementation phase. It is the most important phase where the involvement to make the change. This phase is to analyze business systems, work flow and relationships; then redesign those processes and implement the change 
(ebiz.enable, 2005f). Finally, the commitment phase which is to evaluate the change outcome based on organization goals and validity of those goals which will need continuation on revising and improving the process of change (ebiz.enable, 2005g).

\section{Employee Acquisition, Retention and Ownership}

This aspect focuses on avoiding loss of valued employees and makes the employees pro-active members by resolving their resistance to the change to accepting the change. This will need change assessments in areas such as culture and values (Change management learning center, 2005c). The acquisition and retention will require the project leader to set communication plans that can address the needs of the employees from the front-line to the executives. Retention can be strengthen by providing those needs based on the role of the implementation of the change. Retention and ownership issues can be resolved by applying training and development programs that can provide knowledge about the change and required skills. The ownership of employees should be highlighted by rewards during early success and long-term wins (Change management learning center, 2005b).

\section{Conclusion}

E-business is a change and considered as a global business change. It may affect the whole organization's structure, culture and objectives. This change prospects may differ from firm to another. While it is essential for some organizations to survive, it can be considered as a market competitiveness and leadership approach for others. The best commitment for the change is the management to understand the factors of change and apply the successful ones. The open markets will lead to discover new ideas in marketing and sales. Implementing those ideas may need radical changes in the business or the organization itself. By best practice, applied process of change will need revision and improvement continually.

\section{Reference}

- Answers.com (uda). Reengineering. http://www.answers.com/main/ntquery;jsessionid=4m4r5poaf22pm?tname=reengineering\&meth od=5\&sbid=lc02a\&linktext=reengineering. Accessed 21st Sep 2003.

- Answers.com (udb). strategic management. http://www.answers.com/strategic\%20management\%20. Accessed 21st Sep 2003.

- Chaffey, D. (2004). E-Business and E-Commerce Management. Pearson Education. 
- Chaffey, D., E-consultancy (2005). Managing an E-commerce Team: Integrating Digital Marketing into your Organization. http://www.e-consultancy.com/publications/managingecommerce-team/. Accessed 21st Sep 2003.

- Change management learning center (2005a). Change management - success factors and obstacles. http://www.change-management.com/tutorialsuccess-factors.htm. Accessed 21st Sep 2003.

- Change management learning center (2005b). Change management - the systems and tools for managing change. http://www.change-management.com/tutorialchange-leadership-mod3a.htm. Accessed 21st Sep 2003.

- Change management learning center (2005c). Round 4 - The most effective change management strategies. http://www.change-management.com/tutorialchange-leadership-mod5.htm. Accessed 21st Sep 2003.

- E-Business Solutions, (ud). E-Commerce. http://www.cera.net/sections/ ebusiness/ebusiness_solutions.asp. Accessed 11th Oct 2005.

- E-Business Systems Integration Center, (uda). E-Business: Basic Understanding http://internet.about.com/library/aa_ebiz_051903.htm?terms=e-business. Accessed 21st Sep 2003.

- E-Business Systems Integration Center, (udb). Why e-business: http://internet.about.com/gi/dynamic/offsite.htm?site=http://sic.nvgc.vt.edu/SICstuff\%2DVirtual/ Thompson/WWW/what.htm. Accessed 21st Sep 2003.

- ebiz.enable (2005a). Change Process. http://strategis.ic.gc.ca/epic/internet/ineeef.nsf/en/h_ee00317e.html. Accessed 21st Sep 2003.

- ebiz.enable (2005b). Issues. http://strategis.ic.gc.ca/epic/internet/inee-ef.nsf/en/h_ee00316e.html. Accessed 21st Sep 2003.

- ebiz.enable (2005c). Success Factors. http://strategis.ic.gc.ca/epic/internet/ineeef.nsf/en/h_ee00177e.html. Accessed 21st Sep 2003.

- $\quad$ ebiz.enable (2005d). Preparation. http://strategis.ic.gc.ca/epic/internet/ineeef.nsf/en/h_ee00318e.html. Accessed 21st Sep 2003.

- ebiz.enable (2005e). Acceptance. http://strategis.ic.gc.ca/epic/internet/ineeef.nsf/en/h_ee00322e.html. Accessed 21st Sep 2003.

- ebiz.enable (2005f). Implementation. http://strategis.ic.gc.ca/epic/internet/ineeef.nsf/en/h_ee00320e.html. Accessed 21st Sep 2003. 
- ebiz.enable (2005g). Commitment. http://strategis.ic.gc.ca/epic/internet/ineeef.nsf/en/h_ee00321e.html. Accessed 21st Sep 2003.

- Johnson, G., Scholes, K. (1993). Exploring Corporate Strategy. UK: Prentice Hall.

- Nickels, W.C., Mchugh, J., Mchugh, S. (1990). Understanding Business. Boston: Irwin, Inc.

- Our South West (2004). Managing Change: A guide on how to manage change in an organization. http://www.oursouthwest.com/SusBus/mggchange.doc. Accessed 21st Sep 2003.

- Pettigrew, A.M., Whipp,R. (1993). Managing Change for Competitive Success. Blackwell Publishing.

- PTC Global Services (2005). Product Development System Adoption Services. http://www.ptc.com/services/product_development_system/change_management.htm. Accessed 21st Sep 2003.

- Value Based Management.Net (2005a). 3 Dimensions of strategic change: Pettigrew, Whipp. http://www.valuebasedmanagement.net/methods_pettigrew_dimensions_strategic_change.html. Accessed 21st September 2005.

- Value Based Management.Net (2005b). Change Phases Model - Kotter. http://www.valuebasedmanagement.net/methods_kotter_change.html. Accessed 21st September 2005. 